\title{
Um Negócio de Dois Mundos: Aspectos da Morte no Mundo Físico Transpostos para Memoriais Digitais
}

\author{
Gustavo S. Ueda ${ }^{1}$, Aline Verhalen ${ }^{1}$, Cristiano Maciel $^{1}$ \\ ${ }^{1}$ Instituto de Computação - Universidade Federal de Mato Grosso (UFMT) - \\ Cuiabá - MT - Brazil \\ \{gu.seiji.ueda, alineverhalen, crismac\}@gmail.com
}

\begin{abstract}
The planning of death-related aspects by social web users is reflected on the conception of systems. But what elements related to the planning of these death-related aspects can contribute to systems development in this area? This research is aimed at understanding these aspects, so as to propose useful alternatives to different software, especially digital memorials. To do so, we carried out a literature review and did exploratory research through interviews in commercial places that offer death-related services. As results, we propose reflections on a plan of memorial, considering volitional aspects of digital legacy in digital memorial systems.
\end{abstract}

Resumo. O planejamento de aspectos ligados a morte de usuários na Web Social tem reflexo sobre a concepção de sistemas. Todavia, que elementos relacionados ao planejamento desses aspectos ligados a morte no mundo real podem contribuir para o desenvolvimento de sistemas nesta área? Essa pesquisa visa entender tais aspectos, a fim de propor alternativas úteis a diferentes softwares, em especial, aos memoriais digitais. Para tal, de forma exploratória, e apoiados por pesquisa bibliográfica, foram realizadas entrevistas em ambientes comerciais que oferecem serviços relacionados a morte. Como resultado, são propostas reflexões de um plano de memorial, considerando aspectos volitivos do legado digital em sistemas de memorial digital.

\section{Introdução}

Em sua obra sobre epitáfios, Fanous [2016] contextualiza à evolução das lápides durante os séculos. Na idade média, ele conta que, era nos adros (pátio no entorno das igrejas) que os falecidos eram enterrados, possivelmente marcados de algum modo para identificação e que somente os santos e membros do clero eram enterrados dentro das igrejas. Nos séculos seguintes, a perspectiva sobre as lápides e outros memoriais muda, consequência do senso de identidade individual que surgia. Além disso, com o passar dos séculos o conteúdo dos epitáfios evoluiu, de mensagens de fervor religioso, repreensões aos vivos lembrando do julgamento que entendiam vir, entre outros, aos epitáfios do século XX, que o autor caracteriza pela "inegável tendência" à morte da arte dos epitáfios. Há vários propósitos nos memoriais, sendo eles: registro de fatos e de vidas, expressões de sentimentos, consolo, louvor, denúncias, promoção dos feitos do falecido a até para estímulo aos vivos. Entretanto, em uma perspectiva contemporânea, o desenvolvimento das tecnologias computacionais viabiliza a incorporação de aspectos offline da vida aos 
meios digitais. Isso se relaciona, também, aos aspectos da morte. Assim, as lápides e memoriais foram transpostos aos meios online, por meio dos serviços denominados memoriais digitais [OLIVEIRA et al, 2016; ÖHMAN; FLORID, 2017]. Esse é um dos serviços da área de legado digital pós-morte [MACIEL, PEREIRA, 2014].

Essa transposição da morte ao meio digital incita o conceito que Öhman e Florid [2017] chamam de DAI (Digital Afterlife Industry), "Indústria digital pós-vida", a indústria que volta seus interesses para os interesses dos aspectos pós vida, ligados aos sistemas digitais. Assim, como espaços digitais para recordação e depósito de lembranças e para evitar o limbo de mensagens em contas não mais utilizadas, algumas redes sociais, como o Facebook e Instagram, estão se adaptando e implementaram os memoriais digitais. Essas são as duas redes que Viana et al. [2017] constataram terem a funcionalidade de memorial, dentre as redes sociais analisadas.

Tendo origem no meio físico, fatores offline podem contribuir com a concepção de memoriais digitais. Assim, questiona-se que elementos relacionados ao planejamento de aspectos ligados a morte no mundo real podem contribuir para o desenvolvimento de sistemas nesta área. Essa pesquisa, então, visa explorar contextos fora do espaço virtual para propor reflexões de um plano memorial, considerando aspectos volitivos, os conhecimentos sociais de pessoas que atuam no mercado offline da morte (funerárias e um serviço de placas para lápides) e o "plano de morte" de Tisdale [2018], um guia para pessoas que estão planejando aspectos relacionados a morte.

Para tal, foram realizadas pesquisas de campo em funerárias e cemitérios, cotejadas com a análise bibliográfica, buscando estudos sobre as configurações de memoriais digitais e o estudo do plano de morte. Após transcrição dos dados, num processo de análise interpretativa desses, foi realizada a codificação das falas coletadas nas entrevistas, criando um conjunto de etiquetas relacionadas aos assuntos. Essas etiquetas permitem separar temas e encontrar aqueles mais abordados, para assim saber quais seriam mais adequados a serem considerados em memoriais digitais. Por questões de espaço no artigo, somente parte do processo de etiquetagem será registrado.

Neste artigo, após esta introdução, apresentam-se trabalhos que deram suporte para a pesquisa, em sequência a metodologia, as análises das entrevistas, reflexões para um plano de memorial digital, a conclusão e por fim as referências bibliográficas.

\section{Referencial Teórico}

Para compor esse referencial, foram incluídos trabalhos que trouxessem à tona aspectos voltados a memoriais digitais, que poderiam abranger desde a sua forma do uso, até como isso refletiria nos sentimentos do usuário ou de seu herdeiro. Ainda, buscou-se literaturas que traziam formas com que as pessoas planejam suas mortes, sendo encontrado o Plano de Morte de Tisdale [2018], discutido nesta seção.

Massimi e Baecker [2010] realizaram uma pesquisa com diversas pessoas a fim de descobrir o que os familiares enlutados esperam de um memorial, concluindo-se que, o tempo que se passou desde o falecimento afeta a perspectiva de o que deve ter no memorial. Os autores citam que jovens são os menos preocupados com o fato de ter um legado digital, posto que para a maioria, a morte ainda é algo distante. Tempesta, Pereira e Prates [2018], conversaram com jovens adultos a fim de estudar o sistema Afternote, 
apontando o desafio de antecipar as interações com este sistema. Entre outros, eles percebem que, apesar do dono da conta se utilizar dela para organizar seu legado e sua herança digital, há uma questão emocional que deve ser considerada, dado que não será esta mesma pessoa que irá mexer neste sistema após o falecimento do dono.

Pereira, Maciel e Leitão [2016] observaram ambos os ambientes, memoriais e cemitérios, a fim de buscar as semelhanças que os levam para os memoriais digitais. Em sua pesquisa, foi notada a diferença entre as homenagens feitas em diversas cidades e culturas. Graças a estas observações, é levantado o questionamento de que, apesar de memoriais digitais resolverem o problema de uma falta de gerenciamento de perfis pósmorte, eles trazem uma baixa sensibilidade em se tratando de aspectos culturais. Os autores refletem ainda sobre a importância de ter a data de falecimento nos memoriais.

Tratando de aspectos culturais de cemitérios, os trabalhos de Sheppard-Simms, Simon [2015] e Stahl, Jackson [2019] trazem a discussão sobre o espaço ocupado pelos cemitérios, sendo que Sheppard-Simms e Simon[2015] discutem sobre a forma com que os cemitérios são construídos em Bucareste, se tornando grandes memoriais em todos os cantos da cidades, como praças e até mesmo jardins de casas. Tais espaços acabam se tornando parte da memória local. Enquanto o trabalho de Stahl e Jackson [2019] discute sobre o espaço tomado pelos cemitérios em Sydney, que somado a um certo ar de abandono, causa certo incômodo aos moradores. Este último caso relacionado ao espaço ocupado por memoriais físicos pode ser transportado para os digitais quando se pensa na quantidade de contas inativas, sem o devido cuidado ou atenção. Assim, eles acabam ocupando um espaço na rede social, não cumprindo com a função memorial que teriam como espaço de homenagens, além de ficarem vulneráveis ao mau uso.

Pensando na questão da baixa sensibilidade que os perfis trazem, de Toledo [2018] fez uma pesquisa com usuários envolvendo Design Participativo, no qual o foco era como fazer com que os memoriais mantivessem a personalidade do usuário e os aspectos volitivos. Muitos dos participantes deram sugestões que iam desde mudança de capa até a aceitação de novos amigos, incluindo questões culturais. Foi discutido ainda, de forma inicial, como o memorial poderia ser "pré-configurado" pelos usuários, ainda em vida, alterando, por exemplo, acessos de terceiros e visualização de dados.

De Campos et al. [2017] realizaram um grupo focal com discussões sobre elementos da Web Social em memoriais digitais, e a partir disso, foram elencadas algumas soluções que poderiam alinhar melhor questões de valores humanos e funções técnicas. Foram trabalhados os elementos de Identidade, Relacionamento, Grupos e Volição. Analisando tais elementos, pode-se observar formas de se planejar um memorial digital, dando mais escolhas aos usuários.

O trabalho de Maciel et al [2019] traz uma importante discussão sobre recomendações de Design de memoriais digitais, ressaltando questões que devem ser mostradas nestes memoriais tais como: se houverem vários administradores de uma conta, os nomes destes devem ser visíveis, para que as pessoas saibam quem contatar, também para que possam inserir informações extras no perfil da pessoa, caso faltem dados sobre a mesma, ou hajam coisas incoerentes a respeito dela, buscando torná-lo o mais verídico possível. Recomendações culturais também são trabalhadas neste artigo, que amplia o trabalho realizados por Lopes et al. [2014]. 
O aspecto volitivo dos sistemas computacionais, proposto por Maciel [2011] no âmbito da Web Social, faz com que se possa dar poder para que o usuário possa decidir o que deve ser feito em seu memorial, como deve ser feito, quem deve fazer. Ou seja, torna o memorial mais flexível à escolha do usuário e não somente um conjunto de termos que ele deve aceitar ou não. Nessa perspectiva, ampliam-se as potencialidades de um memorial, como tem sido investigado por alguns dos autores supracitados.

Durante a pesquisa foi encontrado o termo "plano de morte", empregado por Tisdale [2018]. A obra contém um guia para as pessoas que estão planejando aspectos relacionados a sua morte, tratando, entre outros, quem deverá cuidar do funeral e a organização do testamento. É interessante observar o fato de que há detalhes do Plano de Morte que usualmente não são pensados quando há o planejamento da morte, como, quem eu não gostaria que estivesse presente nos ritos funerários. A proposta traz como exemplo o caso de um escritor chamado Terry Pratchett, que deixou em seu testamento que o disco rígido de seu computador, que continha seus livros não finalizados, fosse esmagado por um rolo compressor. Com isso, o autor aponta que, tudo que se tem de durável em sua vida, deverá ser cuidado por alguém no futuro. Assim, um objetivo do plano de morte é garantir que as coisas que ficarão tenham um destino que o dono do plano de morte ache digno, como pode-se considerar o caso do escritor, no qual o destino foi a destruição de parte do que seria seu legado. Além de estabelecer as últimas vontades do indivíduo, que envolvem sua interação com a sociedade, como ritos religiosos e pessoas que quer ver.

\section{Metodologia}

Esta pesquisa exploratória possui abordagem qualitativa [Gil, 2002] e tem como foco a prospecção de informações através de meio empírico, por meio de pesquisa bibliográfica, e entrevistas com profissionais da área fúnebre para obtenção de insights sob os aspectos relacionados ao planejamento da morte.Inicialmente, foram realizadas as leituras bibliográficas supracitadas e, então, houve o interesse em investigar o que se destaca num processo de morte e luto num mundo físico, e como isso pode ser refletido para o mundo virtual, respeitando a vontade da pessoa falecida. Por meio de entrevistas, foi realizado um trabalho de campo a fim de coletar esses dados. Para tal, foram planejadas visitas a estabelecimentos comerciais e profissionais que prestam serviços relacionados a morte, como funerárias e fabricantes de placas para túmulos. Eles se localizavam em torno do Hospital e Pronto Socorro Municipal na cidade de Cuiabá. A fim de viabilizar as entrevistas a serem executadas nestes estabelecimentos, foi elaborado um roteiro de perguntas e um termo de consentimento, explicando aspectos da pesquisa e autorizando o uso dos dados da entrevista. Ainda, esta pesquisa faz parte dos estudos do projeto de pesquisa DAVI (2019), que possui aprovação pelo Comitê de Ética em Pesquisa com Seres Humanos da Universidade Federal do Mato Grosso.

O roteiro servia como guia inicial da entrevista, sem necessidade de ser seguido à risca. Neste guia haviam perguntas sobre o tipo de serviços que o funcionário prestava, até quais eram as preocupações de seus clientes. Ainda, percebeu-se como as pessoas lidavam com as questões das lembranças de entes queridos, como mantinham as memórias e prestavam homenagens para os mesmos. Desta forma, almeja-se identificar aspectos dessa área, desconhecidos pelos pesquisadores e percebidos na fala dos funcionários/proprietários dos estabelecimentos, utilizando-se deste conhecimento social para avançar nas reflexões para o mundo digital. Foram entrevistados, em dezembro de 
2018, por dois pesquisadores do grupo DAVI, um funcionário de cada funerária e o proprietário do serviço de placas, identificados por siglas: funerária 1 (EF1), funerária 2 (EF2) e serviço de placas (ESP). As entrevistas foram transcritas, mantendo-se a forma como os entrevistados se expressavam, exceto quando o entendimento era comprometido.

Para analisar esses dados, foram selecionados trechos de cada entrevista, que exprimiam alguma informação sobre o tema. Os trechos foram dispostos verticalmente na terceira coluna de uma tabela e as duas primeiras colunas identificavam o entrevistado com base nas siglas estabelecidas (EF1, EF2, ESP), sem menção ao nome de nenhum deles, utilizando-se somente das siglas, e enumerando os fragmentos de cada entrevista. Desse modo, as citações de EF1 são identificadas de 1 a 14, as de EF2 de 1 a 12 e as de ESP de 1 a 32. Para viabilizar esse processo de análise, optou-se por gerar etiquetas que agrupassem os fragmentos segundo assuntos comuns. Para tal, uma quarta coluna foi inserida, que contém palavras e frases isoladas que sintetizam esses assuntos. A partir disso, foram adicionadas outras cinco colunas, quatro para etiquetas e uma outra coluna, que continha explicações, comentários, observações e debates sobre os trechos que colaboraram com a concretização das etiquetas.

As etiquetas foram então debatidas em quatro reuniões entre os pesquisadores do grupo, atuantes na área de tecnologias associadas a morte. Nesses debates, agruparam-se etiquetas. Simultaneamente, enquanto se decidiam as etiquetas, foram formuladas definições delas no contexto de memorial digital, unindo as definições do dicionário online de português Dicio [2019], com os sinônimos do dicionário online de Sinônimos [2019]. Durante o processo de consolidação das etiquetas, entendeu-se que era necessário especializá-las em subetiquetas pois alguns agrupamentos eram muito amplos, não contemplando aspectos importantes. Além disso, um trecho poderia receber mais de uma subetiqueta de um mesmo grupo de etiquetas. Por fim, foram formadas vinte e oito etiquetas e subetiquetas, apresentadas e analisadas a seguir.

\section{Análise das Entrevistas e Etiquetagem}

Tabela 1. Etiquetas e subetiquetas.

\begin{tabular}{|c|c|}
\hline Etiqueta & Subetiqueta \\
\hline $\begin{array}{l}\text { Identidade: Conjunto de } \\
\text { qualidades, características, } \\
\text { particularidades e aspectos } \\
\text { de uma pessoa que tornam } \\
\text { possível sua identificação. } \\
\text { Aquilo que seria a essência } \\
\text { do indivíduo. A identidade } \\
\text { de um indivíduo é } \\
\text { propagada para o } \\
\text { memorial e nos ritos } \\
\text { fúnebres. }\end{array}$ & $\begin{array}{l}\text { Objetos: Toda coisa material perceptível por algum dos sentidos, que é } \\
\text { motivo de sentimento ou ação. Essa etiqueta relaciona-se com objetos } \\
\text { materiais ligados ao falecido, sendo parte da expressão de sua } \\
\text { identidade. } \\
\text { Aparência: A parte visual física de um indivíduo. Expressa a } \\
\text { identidade, quando se atende aos desejos do indivíduo sobre seu } \\
\text { corpo. } \\
\text { Dignidade: Característica que permite ser digno, manter o respeito, } \\
\text { decência, integridade e honra de um indivíduo. } \\
\text { Dados Gerais: Nome, data de nascimento e foto. Correlaciona-se com } \\
\text { os Aspectos de Memorial, porém trata de informações gerais que o } \\
\text { usuário detém em vida. }\end{array}$ \\
\hline
\end{tabular}


Herdeiro: Relaciona-se a pessoa que recebe a responsabilidade moral de configurar, manter, gerir 0 memorial e propagar as vontades do falecido.
Empecilho: Algo que dificulta o herdeiro de tomar atitudes a respeito do memorial herdado.

Desinteresse: Relaciona-se aos casos em que o herdeiro apresenta ao menos uma das seguintes características: falta de interesse, falta de zelo, é indiferente ou negligente com o memorial que herdou.

Não Reclamados: “[...] 'não reclamados': o termo designa corpos que não foram retirados do IML por familiares. Embora a maior parte dos cadáveres não reclamados seja formada de corpos 'desconhecidos', há casos em que o cadáver é identificado e a família, por razões diversas, não toma nenhuma providência a respeito da liberação do corpo e do sepultamento." (Rezende, 2012, p. 40-41 apud DE OLIVEIRA et al, 2018, p. 04-04)

Ritos: Trata do conjunto de regras, cerimônias e práticas com significado simbólico ou religioso de um grupo. Também se refere a reunião de normas sociais, como "rito de passagem". São os aspectos ligados a cultura e identidade presentes em ritos de morte e que são presentes como características de memoriais.

Religião: Trata das manifestações, comportamentos morais e intelectuais resultantes de crenças em forças superiores (sobrenaturais), presentes nos memoriais e na morte.

Futebol: Expressões relacionadas ao esporte futebol nos memoriais e ritos fúnebres.

Maçonaria: Relaciona-se às expressões desse grupo em ritos, regras e em aspectos nos memoriais.

Aspectos de Memorial: Pormenores, componentes, partes de um memorial.

Epitáfio: Relativo aos textos colocados sobre os monumentos funerários (memoriais), normalmente uma homenagem ao falecido, mas nem sempre o falecido é o foco.

Data de Falecimento: A data ou somente o ano de falecimento do usuário. De certo modo, completo da subetiqueta de Dados Gerais, tratando da data de falecimento, um dado que o usuário terá após sua morte.

Nesta seção são apresentadas etiquetas e subetiquetas que proporcionaram a análise das transcrições das entrevistas e seus significados, com descrição contextualizada ao estudo. O conjunto de dezessete etiquetas com subetiquetas está sumarizado na Tabela 1 e ,de forma a exemplificar esse processo, são exemplificadas a seguir informações qualitativas, ou seja, a fala dos sujeitos com a referida etiqueta.

No serviço de placas, o trabalhador diz que os clientes, quando planejam a placa de lápide, buscam fotos e "mensagens" (epitáfios) que possibilitam sentir, identificar o falecido. Isso possibilita que parentes e outras pessoas ligadas ao falecido busquem formas de personalizar a homenagem ao falecido. Isso é percebido no trecho de ESP-1, quando diz: "Ele quer colocar exatamente, assim... Uma foto que a pessoa, o parente ou o familiar vai olhar e vai sentir que aquilo ali é a pessoa. A mensagem é a mesma coisa[...] se a pessoa acaba lendo, o que acontece: [...] ele vai senti aquela emoção e vai senti que a mensagem pode tê até te saído daquela pessoa mesmo [...]". Esse trecho foi abordado tanto na etiqueta de Identidade, quanto na de Aspectos do Memorial.

No que se refere ao herdeiro, esse normalmente é descrito como sendo parente(s) ou pessoas mais próximas do falecido e são eles quem especificam as decisões relacionadas ao morto, como pode-se perceber na fala do funcionário da funerária EF1- 
4: "Deixa tudo especificado para as filhas, alguém mais próximo [...]”. Porém, há casos em que não se encontra um desses herdeiros para representar as vontades do falecido. No mundo físico, isso está associado aos casos de "Não Reclamados" e são, por isso, tomadas decisões sobre o sepultamento que não são fornecidas pelos herdeiros do caso anterior, outra entidade tem de responder pelo falecido. Essa situação é abordada no trecho EF211: "[...]aquelas pessoas que são mais sozinhas que vem pra fora, que fica em casas de apoio. Aí tem só uma assistente social cuidando dela ali, aí ela vem a óbito. Nesses casos, ela, a assistência social, não consegue encontrar a família, não consegue encontrar nada, a assistente social vem e solicita o serviço né? E aí é sepultado aqui mesmo.”.

Os motivos pelos quais os herdeiros não tomam decisões sobre o falecido podem não ser somente o fato de não serem encontrados, outro motivo pode ser o próprio Desinteresse deles. No trecho ESP-11: "Vamo fala aí 60\% das pessoas que vem na minha loja, ele acaba fazendo uma praca bunita, conforme ele quer, como ele acha que combina com a pessoa, por conforto dele e conforto da família. [...] E conforme, talvez, o ente querido queria ou desejava. Mas tem algumas pessoas que faz mais [...] por fazer. [...] Pra num deixa o túmulo vago, sem nada[...]. E tem pessoas que chega aqui falando 'ó eu quero uma praca... Não. Do qualquer jeito que você fizer tá bom.' Tipo assim, joga totalmente a responsabilidade pra mim.". O funcionário estima, segundo seus referenciais, a quantidade de clientes que fazem as placas como uma obrigação, sem necessariamente se importarem com as vontades ou em representar o falecido e também diz que a responsabilidade de criar os modelos recai sobre ele. Há casos, ainda, em que a falta de vínculo com o falecido faz com que o herdeiro não faça a placa, como no trecho ESP-14: "Algumas pessoas, [...] ele num tem aquele vínculo com a pessoa que faleceu. Tendeu? Tipo assim, não tinha harmonia, não tinha contato ou tipo assim 'ah eu vô fazê só por fazer', então acaba num fazendo".

Sobre Cultura, talvez, tão influentes quanto as questões religiosas, estão os times de futebol. Por isso são comumente colocados nas placas de lápides, podendo até, como relatado, substituir os epitáfios, ESP-4: "Comum? Sim. Ala ó[...], pessoas que acabam colocando nome da pessoa completo, data de nascimento e ao invés de colocar uma mensagem, ele acaba colocando um símbolo, Flamengo, Corinthians [...] e assim em diante.".

Ainda, foram criadas onze etiquetas que não tem ramificações e demandariam de mais análises no processo de etiquetagem, a saber: Planejamento da morte, Desejo, Celebração, Homenagem, Luto, Financeiro, Emoção, Manutenção, Tempo, Sentimento e Segurança. Para Luto, por exemplo, expõe-se como a interação das pessoas e herdeiros com os memoriais e lembranças do falecido influenciam o processo de luto. Ao interagirem com lembranças se dão conta da ausência da pessoa, enquanto se confortam com os momentos vivenciaram com o falecido, ESP-16: "você absorver que a pessoa, que você amava ou gostava, faleceu. [...] "Exempru”, tem pessoas que é... buscam álbum, é... sites de relacionamento [redes sociais, no geral] ou uma página da internet que tinha todas as fotos, ou o próprio álbum [físico], pra ele vê, fica olhando, ali assim... curtindo aquele momento que, talvez, eles se "curtiram ali" [...] ou [...] eles vão olha aquela foto e vão se sentir melhor, vai sentir mais confortável. E, talvez, com a pessoa administrando, ele pode ter, assim... ele pode absorver isso mais rápido, acostumar com a ausência da pessoa física.". O entrevistado, ainda, argumenta que o herdeiro ao administrar um memorial digital teria um processo de luto mais rápido. 


\section{Reflexões para um Plano de Memorial Digital}

Quando analisadas as etiquetas e suas subetiquetas, percebem-se vários aspectos que são abordados pelas pessoas enlutadas, na visão de pessoas que trabalham com isso diariamente. Muitos destes aspectos são mostradas como resultados da vontade da pessoa que faleceu e reforçam a ideia de um plano "de morte", como discutido por Tisdale [2018], no mundo físico. Busca-se então, para o mundo digital, um plano de memorial, que seria uma forma de melhor organizar a herança e as vontades de um usuário em redes sociais, antes do perfil dele se tornar um memorial digital.

Tem-se assim uma visão de vários setores que precisam ser repensados para que o gerenciamento do memorial seja realizado de forma a ser acolhedor tanto para o falecido dono da conta, de modo a ser uma homenagem, tanto para seu herdeiro. A fim de alcançar este objetivo, utilizou-se de pesquisa de campo e etiquetagem para demarcar aspectos importantes de um memorial digital. Reflexões iniciais com base neste processo são colocadas a seguir.

No que tange a Identidade de uma pessoa, um memorial digital poderia contemplar alguns aspectos levantados na etiquetagem. Elementos importantes foram previamente abordados por outros autores, como por exemplo, a data de nascimento [Pereira et al., 2016] ou a foto como identificador do usuário [De Toleto, 2018]. Sugerese ainda que quando a foto de perfil não for uma foto da pessoa (ex. foto de flores, animais), seja possível colocar mais uma foto, respeitando assim seu gosto, mas ainda dando formas de identificá-la. Este aspecto também pode se enquadrar quando a pessoa colocou uma foto muito antiga. Outra sugestão é ter espaços para deixar imagens específicas, que tenham relação com a pessoa, como os objetos deixados em um túmulo.

Com relação ao Herdeiro, esse é provavelmente um dos aspectos mais amplos para discussão, levando em conta sua importância quanto ao aspecto de manutenção do memorial. As responsabilidades e interesses de um herdeiro [Brubaker, 2014; Maciel et al., 2015] e questões de cunho emocional [Tempesta, Pereira e Prates, 2018], podem afetar a gestão desse memorial, gerando até uma estagnação dele. A etiquetagem nos permite refletir sobre questões necessárias neste sentido, como a necessidade de: verificar o interesse do herdeiro em manter aquele memorial, uma vez que atualmente as redes tem apenas informado ao herdeiro em vida; e haver um segundo herdeiro para administrar o memorial, caso o primeiro apesar de interessado, não tenha condições físicas e/ou emocionais, mesmo que durante um tempo.

Muitas das etiquetas de Sentimentos têm ligação a aspectos da etiqueta Herdeiro, pois lidam diretamente com questões de comoção e até de impotência face a morte. Elas também podem ser associadas à etiqueta Aspecto Memorial em se tratando de epitáfios. Assim, seria possível no plano de memorial deixar que o usuário em vida ou o herdeiro insira um epitáfio, que seja significativa para o memorial desta pessoa.

Com relação a sub-etiqueta Religião, da Cultura, reforça-se o cuidado identificado por autores como Lopes et at. [2014] e Pereira et al. [2016], quanto a inserção de símbolos religiosos. Da Cultura, sugere-que que seja possível pré-configurar símbolos religiosos de acordo com a religião especificada pelo usuário, caso haja, e elementos ligados ao time de futebol do usuário, caso haja.

As reflexões apresentadas fazem parte das análises iniciais com base nos dados 
coletados. Eles devem compor um "plano de memorial", a ser pré-configurado por um usuário em vida, de maneira volitiva. Todavia, se não realizado, e havendo um herdeiro, elas poderiam ser configuradas por ele. Ainda, cabe refletir que algumas redes sociais têm esses elementos previamente configurados no perfil do usuário, como o time de futebol, por exemplo. Todavia, a transição desses elementos ou não para um memorial seria uma nova decisão, presente no "plano de memorial".

\section{Considerações finais}

Com o objetivo de explorar contextos fora do espaço virtual na concepção de sistemas memorial, foram considerados o próprio memorial, seus aspectos com base nas etiquetas e os trabalhos analisados. Assim, pode-se observar alguns aspectos nos quais são necessárias melhorias, muitos tidos como recomendações. Essas melhorias no geral, podem ser atribuídas em parte ao sistema, como o caso atual que o Facebook faz, ao criar uma página automática e neutra de um memorial a partir do perfil do usuário. Todavia, para haver realmente uma mudança que possa abranger as reflexões apontadas nesta pesquisa, e importante que haja uma forma de organizar e perguntar ao usuário seus últimos desejos, o que resultaria no Plano de Memorial. Esse traria diversas opções ao usuário, a fim de deixá-lo livre para escolhê-las ou guiando o herdeiro. Parte-se do princípio que essa funcionalidade seria usada pelos usuários, mas face aos tabus da morte, essa questão merece ser mais bem investigada.

Os desafios encontrados durante a realização da pesquisa são inerentes a pesquisa de campo, todavia com a particularidade de exploração desta temática. Teve-se cuidado desde o momento da elaboração dos questionários, na definição dos locais para as entrevistas, na abordagem aos entrevistados de forma a extrair os conhecimentos sociais destes e no tratamento dos dados, incluindo a transcrição e análise. Também foi importante manter tudo documentado de forma a não perder detalhes importantes. Porém, registros de imagem foram mais limitados por questões comerciais. Em especial, a etiquetagem das falas foi um processo extremamente lendo e cuidadoso. Percebe-se que, com base nas falas dos sujeitos, etiquetadas, será possível realizar mais inferências e reflexões, sendo o que se apresenta um resultado inicial deste processo. Também, o rico conjunto de etiquetas gerado pode ser útil na organização de aspectos importantes no campo de memoriais, útil para outras pesquisas.

Com base nas reflexões geradas, na literatura e no que mais possa ser explorado nesta temática, visa-se elaborar um Plano de Memorial, a fim de mostrar de forma mais ampla essa funcionalidade que um usuário poderá ter acesso para tomar as decisões do seu futuro memorial. Neste sentido, recomendações mais completas, acompanhadas de protótipos e exemplos, podem ser desenvolvidas para pesquisas futuras.

\section{Referências}

Brubaker, Jed R. et al. Stewarding a legacy: responsibilities and relationships in the management of post-mortem data. In: Proceedings of the SIGCHI Conference on Human Factors in Computing Systems. ACM, 2014. pp. 4157-4166.

de Campos, K. L., Justi, T., Maciel, C., \& Pereira, V. C. (2017). Digital Memorials: A proposal for data management beyond life. In Proceedings of the XVI Brazilian Symposium on Human Factors in Computing Systems (p. 23). ACM.

de Oliveira, D. D., de Jesus, S., \& Aguiar Filho, A. M. (2018). 3. Corpos indigentes: a 
identificação dos corpos com identidade ignorada encontrados no Estado de Goiás Indigent bodies: the identification of bodies found with ignored identity in the State of Goiás. Revista Brasileira de Ciências Criminais, 2018, 04-04.

de Oliveira, J.; Amaral, L.; Reis, L.P.; Faria, B.M. A study on the need of digital heritage management plataforms. In: Information Systems and Technologies (CISTI), (2016) 11th Iberian Conference on. IEEE, 2016. p. 1-6.

de Toledo, T. J. (2018) [Novas soluções para identidade e volição em memoriais digitais no Facebook. Trabalho de Conclusão de Curso. (Graduação em Ciência da Computação) Universidade Federal de Mato Grosso.]

DAVI. Projeto Dados Além da Vida. 2016. PROPEQ/UFMT. Acesso em: Aug 08, 2019 Disponível em: <http://lavi.ic.ufmt.br/davi/>.

Dicio. Dicionário Online de Português. 2019. Disponível em: 〈https://www.dicio.com.br〉 Acesso em: 11 jul. 2019.

Fanous, S. Epitaphs: A Dying Art. Oxford: Bodleian Library, 2016

Gil, A. C. (2002). Como classificar as pesquisas. Como elaborar projetos de pesquisa, 4, 44-45.

Lopes, A. D., Maciel, C., \& Pereira, V. C. (2014). Recomendações para o design de memórias digitais na web social. In Proceedings of the 13th Brazilian Symposium on Human Factors in Computing Systems pp. 275-284. Sociedade Brasileira de Computação.

Maciel, C. ; Pereira, V., (2014). A morte como parte da vida digital: uma agenda de pesquisa em IHC. In Proceedings of the 13th Brazilian Symposium on Human Factors in Computing Systems (pp. 441-444). Sociedade Brasileira de Computação.

Maciel, C. et al. Recommendations for the Design of Digital Memorials in Social Web. In: International Conference on Human-Computer Interaction. Springer, Cham, 2019. p. 64-79.

Maciel, C.; Pereira, V.C. ; Sztern, M.. Internet Users: Legal and Technical Perspectives on Digital Legacy Management for Post-mortem Interaction. In: Human Interface and the Management of Information. Information and Knowledge Design. HIMI 2015. Lecture Notes in Computer Science, Springer, Cham, vol 9172, pp. 627-639.

Massimi, M., \& Baecker, R. M. (2010). A death in the family: opportunities for designing technologies for the bereaved. In Proceedings of the SIGCHI conference on Human Factors in computing systems (pp. 1821-1830). ACM.

Öhman, C.; Florid, L. The political economy of death in the age of information: a critical approach to the digital afterlife industry. Minds and Machines, v. 27, n. 4, p. 639-662, 2017.

PEREIRA, Vinícius Carvalho; MACIEL, Cristiano; LEITÃO, Carla Faria. The design of digital memorials: scaffolds for multicultural communication based on a semiotic analysis of tombs. In: Proceedings of the 15th Brazilian Symposium on Human Factors in Computing Systems. ACM, 2016. p. 25..

Sheppard-Simms, E.; Simon, K. The Institution of Perpetual Memory: The Typology of the Cemetery and the Generative Potential of Renewable Tenure. In: SAHANZ 2015. Society of Architectural Historians Australia and New Zealand, 2015. p. 603-615.

Sinônimos. Dicionário de Sinônimos Online. 2019. Disponível em: <https://www.sinonimos.com.br> Acesso em: 11 jul. 2019.

Stahl, I.; Jackson, B. L. Sudden death memorials in Bucharest: distribution in time and space. In: Yearbook of Balkan and Baltic Studies 2019. v. 2, p. 37-56.

Tempesta, F., Pereira, F. H., \& Prates, R. O. (2018). Young Adults' Perspective on Managing Digital Legacy: An Analytical and Exploratory Study. In Proceedings of the 17th Brazilian Symposium on Human Factors in Computing Systems (p. 42). ACM.

Tisdale, S. Advice For Future Corpses* - A Practical Perspective on Death and Dying* And Those Who Love Them. Gallery Books. 2018

Viana, G. T. et al. Análise dos termos de uso e políticas de privacidade de redes sociais quanto ao tratamento da morte dos usuários. In: Anais do VIII Workshop sobre Aspectos da Interação Humano-Computador para a Web Social. SBC, 2017. p. 82-93. 